\title{
Development and Implementation of Interactive/Visual Software for Simple Aircraft Gas Turbine Design
}

\author{
Afshin J. Ghajar, Ronald D. Delahoussaye, Vandan V. Nayak \\ School of Mechanical and Aerospace Engineering, Oklahoma State University \\ Stillwater, OK 74078 \\ ghajar@ceat.okstate.edu
}

\begin{abstract}
This paper describes a versatile, user-friendly, and easy to understand software suite that has been developed for analysis and design of a simple turbojet engine. The software has been class room tested for several semesters and it was very well received by the students.

\section{Introduction}

The school of Mechanical and Aerospace Engineering at Oklahoma State University offers MAE 4243, "Gas Power Systems", as a required course for the Aerospace Engineering degree and an elective course for the Mechanical Engineering degree. Student use of software to analyze and design gas turbine systems has been an important part of this course since 1988 . Use of software has been particularly important in the "design project" phase of the course. The software in use for many years was developed in the DOS environment and lacked many of the ease-of-use features now commonly available in MS Windows style programs. In addition, the source code for the program was not available to allow faculty and students to correct perceived weaknesses in the program. The primary goal of this project was to develop MS Windows based software: Simple Aircraft Gas Turbine Design, that is easy to use, maintain and update, and can be distributed freely.
\end{abstract}

This software development project contributed in a synergistic way to three different educational missions. It provided a high quality MS level creative component project for the MS student who developed the software. The software is now being used by undergraduates in MAE 4243. The software was written in a modular and expandable way so that it can and has been used for additional research work by MS students.

This paper will describe the components of a Simple Aircraft Gas Turbine, define the thermodynamic cycle implemented in the model, define the key engine performance measures calculated by the model, and describe the calculation of the thermodynamic properties of air for varying altitudes. The capabilities and current limitations of the software will be described. Instructor and student assessments of the contribution of this software to the learning process will be given.

\section{Components of a Simple Aircraft Gas Turbine}

A simple aircraft gas turbine is nothing but an engine used to convert fuel energy to a more useful form of high speed thrust for a jet aircraft. A typical gas turbine consists of a diffuser, compressor, combustion chamber, turbine and nozzle, as shown schematically in Figure $1^{1}$.

Diffuser: For a turbojet aircraft engine, the airflow entering the compressor must have a low Mach number, in the range of 0.4 to 0.7 , to prevent air separation on the compressor blades. 
The purpose of the diffuser is therefore to reduce the high-speed airflow to lower speeds and also act as a pressure recovery device.

Compressor: The basic purpose of a compressor is to increase the pressure of the gas entering it. The high-pressure air coming out of the compressor is one of the important factors in the generation of thrust by the engine. Compressor pressure ratio (CPR) along with adiabatic efficiency and work are the important performance factors of the compressor.

Combustor: The high-pressure air from the compressor is fed into the combustor where it is mixed with fuel and ignited. The main purpose of the combustor is to raise the temperature and the enthalpy of the working fluid.

Turbine: A turbine is a device, which converts the enthalpy and kinetic energy of a moving fluid into some form of mechanical work. The gas turbine is used to convert the enthalpy of working fluid to shaft work, which can then be used to run the compressor and other auxiliaries.

Nozzle: The nozzle is the component, which produces thrust in a turbojet engine. The high pressure air exiting the turbine is accelerated to high velocity before exiting the nozzle. The nozzle exit static pressure $\left(\mathrm{p}_{5}\right)$ is the same as the inlet static pressure $\left(\mathrm{p}_{0}\right)$.

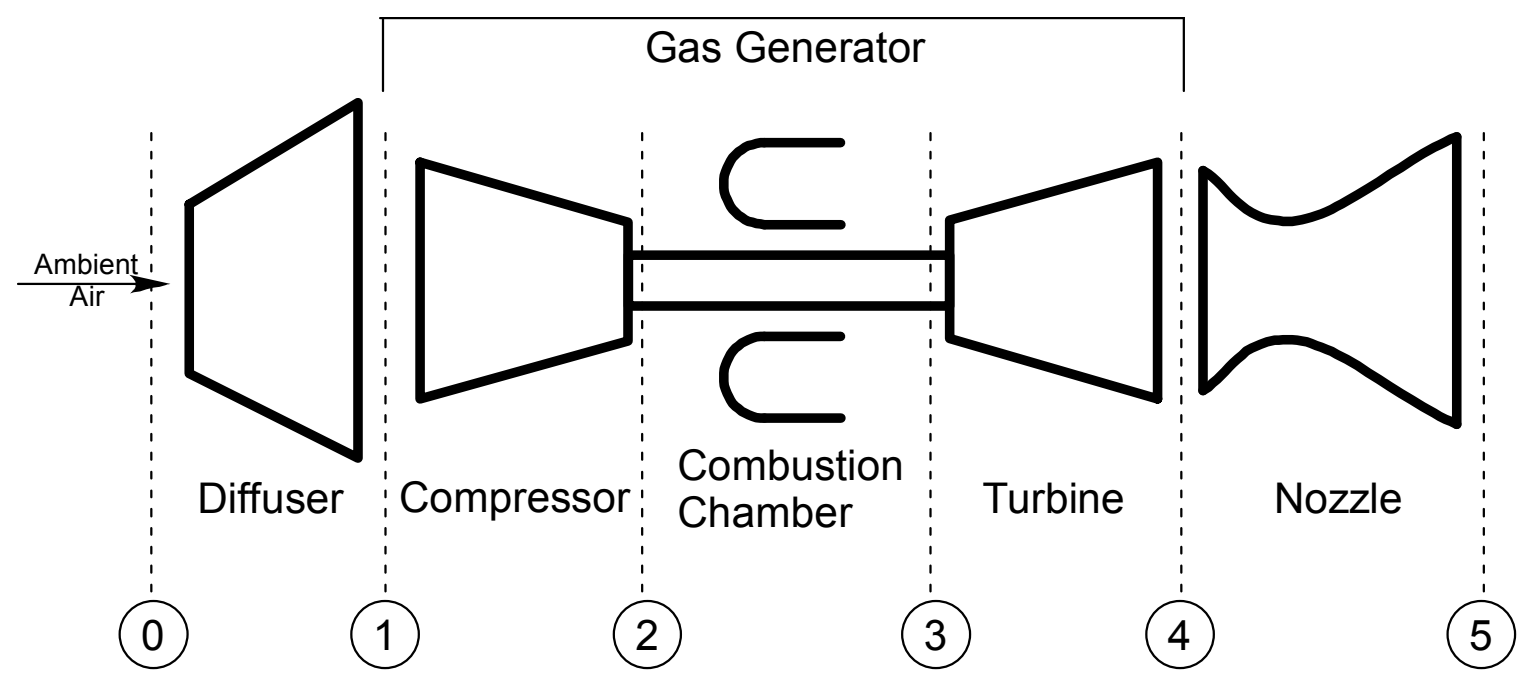

Figure 1. Schematic diagram for non-afterburning turbojet engine. ${ }^{1}$

A turbojet is one of the several types of gas turbines used to propel an aircraft. The others used are turbofan and turboprop. The turbofan engine contains all the elements of the turbojet mentioned, but in addition there is a large fan at the front, which increases airflow rate requiring more power from turbine, reducing exit velocity and increasing propulsion efficiency. The third type is a turboprop engine, in which propulsion is accomplished through combined action of a propeller at the front of the engine and thrust produced by exhaust gases from gas turbine. This project deals with the design of 'non-air standard' 'non-afterburning' turbojet engine. 
The term 'air standard' assumes that air is the only working fluid throughout the cycle and a heat addition process replaces the actual combustion chamber. However, the effects of fuel addition in the combustion chamber on the turbine and nozzle property calculations were considered, and also on the performance characteristics of the gas turbine.

An afterburner is an extension of the engine, used to reheat gases leaving the turbine so that the momentum of the gases leaving the engine exit can be increased. The gas turbine design under consideration does not include the afterburner hence it is specified as a 'non-afterburning' turbojet engine.

Several assumptions we made so as to simplify the analysis of the gas turbine:

1) The properties, at the inlet and outlet states of the compressor, combustion chamber and turbine, used to define various component efficiencies and pressure drop are 'stagnation' (total) properties.

2) A pressure drop is assumed in the combustion chamber.

3) The actual work of the turbine is not the same as that of the compressor since mass of the working fluid changes after addition of fuel in the combustion chamber.

4) The final exit pressure of the nozzle is the same as the inlet pressure of the diffuser. Both of these are static pressures since they are theoretically 'outside' of the engine.

5) Air properties are calculated using both variable and constant specific heat assumptions

Variable specific heat assumption is one where the specific heat of the air is calculated at each state depending on its temperature at that state. Constant specific heat assumption simplifies the calculations however the calculated results could be considerably different than results based on variable specific heat.

Figure 2 illustrates the individual processes in a turbojet cycle on a T-s diagram. The states $0-5$ on the diagram correspond to the states shown in Figure 1. The states on the diagram labeled with the letter ' $a$ ' are actual states, and the states labeled with the letter ' $i$ ' are ideal states. The subscript ' $t$ ' refers to the stagnation or total state. 


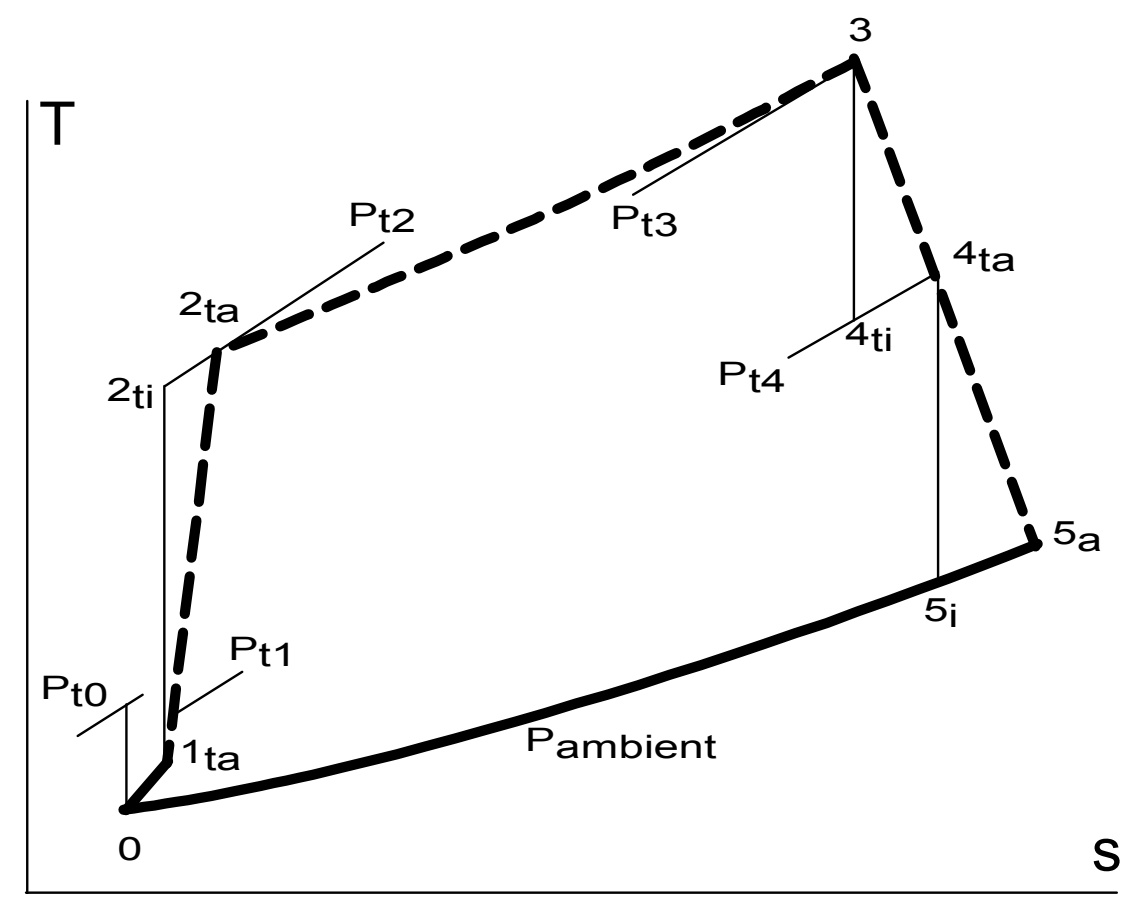

Figure 2. Temperature entropy (T-s) diagram for a non-afterburning turbojet engine with nozzle expansion back to ambient pressure. ${ }^{1}$

\section{Computation of Thermodynamic Properties of Air}

A 'Simple Aircraft Gas Turbine' was modeled as a sequence of thermodynamic processes describing the stages of the gas turbine. The analysis of individual components for a 'Simple Aircraft Gas Turbine' required calculation of thermodynamic properties of air at each of the stages of the gas turbine. It was thus essential for the design of the gas turbine that the gas properties computed at each stage be accurate. The thermodynamic properties of air cannot be computed directly from a given set of equations, as air comprises of a mixture of nitrogen, oxygen and argon. It was thus necessary to calculate the properties of each of these individual gases before calculating the properties of air. The properties needed for thermodynamic analysis of the gas turbine were:
a) Specific Heat
b) Enthalpy
c) Internal Energy
d) Absolute Entropy
e) Relative Pressure
f) Relative Volume

The properties were calculated using procedures detailed in References 2-5, using up to $7^{\text {th }}$ order polynomial approximation with empirical coefficients. The maximum percentage error for all values was found to be less than $0.48 \%$. 


\section{Computation of Atmospheric Temperature and Pressure Varying with Altitude}

Because a gas turbine must operate through a wide range of altitudes, and the properties of air vary substantially with altitude, it was necessary to quantify the variation of air temperature and pressure with altitude. The earth's atmosphere has been divided into seven distinct levels for sake of convenience. The values of temperature and pressure at these different geopotential altitudes ranging from $0 \mathrm{~km}$ to $84.852 \mathrm{~km}$ can be calculated from the equations for temperature and pressure from Reference 6.

\section{Performance Characteristics of a Gas Turbine Engine}

After a complete thermodynamic analysis to determine all of the "state" values for the engine has been performed, several key measures of the performance of the engine may be computed.

Thrust $(\tau)$ : Thrust is a mechanical force, which is generated by the reaction of accelerating a mass of gas. The aircraft gas turbine does work on the gas (air) as result of which the gas (air) is accelerated to the rear, the aircraft then is accelerated in the opposite direction. This acceleration produces a force on the aircraft, which helps it in overcoming the drag forces (air resistance) on the aircraft and move forward.

Specific Thrust (I): The specific thrust is defined as the thrust produced when a unit mass of air per unit time enters the gas turbine.

Thrust Specific Fuel Consumption (TSFC): The thrust specific fuel consumption is defined as the mass of the fuel added per unit of time divided by the thrust produced by the gas turbine engine.

Propulsion Efficiency $\left(\eta_{p}\right)$ : Propulsion efficiency of a gas turbine engine is defined as ratio of the thrust power to the jet power. Thrust power is defined as the product of the thrust and the inlet velocity of air or flight velocity. Jet power is the change in kinetic energy of gases while passing through the gas turbine engine.

Thermal Efficiency $\left(\eta_{\text {th }}\right)$ : The thermal efficiency of a gas turbine engine is defined as the ratio of the change in kinetic energy of the gases passing through the gas turbine engine to the rate at which energy is added to the gas turbine engine.

Overall Efficiency $\left(\eta_{\mathbf{0}}\right)$ : The overall efficiency of the gas turbine engine is defined as the product of the thermal efficiency and the propulsion efficiency.

Aircraft Range (S): The total distance the aircraft can travel with a given mass of fuel.

\section{Simple Aircraft Gas Turbine Design - Software Suite}

Based on the modeling and analysis techniques described earlier, three different software tools have been produced and are described below. The programs are: Altitude, Gas Thermodynamic Properties and Simple Aircraft Gas Turbine Design. 
Altitude Program: The 'Altitude' software is a tool to calculate the atmospheric temperature and pressure for any given altitude. This program is a very simple one. It has only one screen as shown in Figure 3. The Altitude is entered, and the air temperature and pressure are computed and displayed, in the selected unit system.

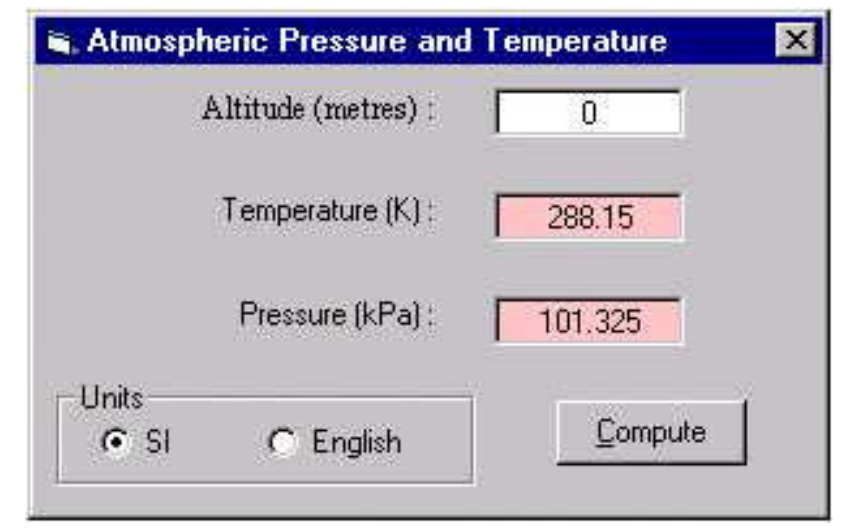

Figure 3. 'Altitude' program.

Gas Thermodynamic Properties Program: The 'Gas Thermodynamic Properties' software is a standalone tool to calculate thermodynamic properties of various ideal gases. The major features are as follows:

1) Calculate thermodynamic properties of several ideal gases, including Air, Carbon Dioxide, Hydrogen, Oxygen, and many others.

2) Generate thermodynamic table for an ideal gas for a given temperature range.

3) Compute the absolute temperature of an ideal gas given the value of any of its thermodynamic properties, i.e. of enthalpy, absolute entropy, internal energy, relative pressure, relative volume and specific heat. This feature helps the user since he/she does not have to carry out linear interpolation so as to compute the absolute temperature of ideal gas.

4) Compute thermodynamic properties of any 'User Defined' gas. The user must provide the gas constants for a 'User Defined' gas before computing its properties.

The main screen of the 'Gas Thermodynamic Properties' software is shown below in Figure 4, and a sample table of properties produced by the program is shown in Figure 5. 


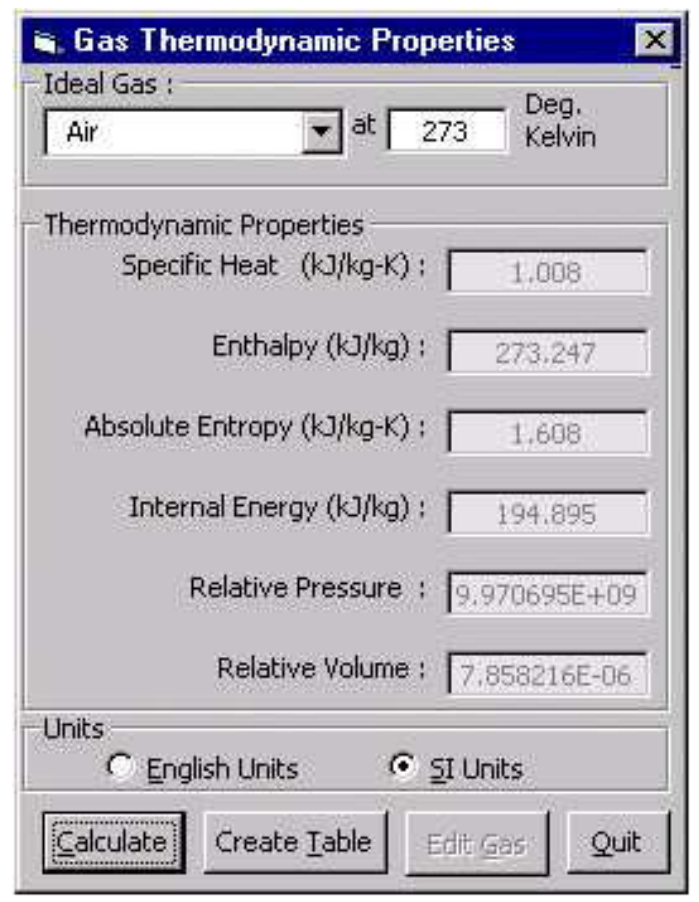

Figure 4. Gas Thermodynamic Properties Program opening screen, showing Air as the selected gas, and the gas properties corresponding to a user specified temperature of $273 \mathrm{~K}$.

\begin{tabular}{|c|c|c|c|c|c|c|c|}
\hline \multicolumn{6}{|c|}{ 4. Thermodynamic Properties of Ideal Gases } & \multicolumn{2}{|c|}{$-\square \sqrt{x}$} \\
\hline \multicolumn{8}{|l|}{ File } \\
\hline \multicolumn{7}{|c|}{ Thermodynamic properties for gas : Air } & $\triangle$ \\
\hline $\begin{array}{l}\text { Absolute } \\
\text { Temp. } \\
\text { (DegK) }\end{array}$ & $\begin{array}{c}\text { Specific } \\
\text { Heat } \\
(\mathrm{kJ} / \mathrm{kg}-\mathrm{K})\end{array}$ & $\begin{array}{r}\text { Enthalpy } \\
(\mathrm{kJ} / \mathrm{kg})\end{array}$ & $\begin{array}{l}\text { Absolute } \\
\text { Entropy } \\
(\mathrm{kJ} / \mathrm{kg}-\mathrm{K})\end{array}$ & $\begin{array}{c}\text { Internal } \\
\text { Energy } \\
(\mathrm{kJ} / \mathrm{kg})\end{array}$ & $\begin{array}{l}\text { Relative } \\
\text { Pressure } \\
\left(10^{\wedge}-10\right)\end{array}$ & $\begin{array}{c}\text { Relative } \\
\text { Uolume } \\
\left(15^{\wedge} 8\right)\end{array}$ & \\
\hline 200.0 & 1.010 & 199.97 & 1.295 & 142.57 & 0.336 & $1,759.393$ & \\
\hline 300.0 & 1.099 & 300.35 & 1.702 & 214.25 & 1.387 & 620.923 & \\
\hline 400.0 & 1.017 & 401.14 & 1.992 & 286.34 & 3.808 & 301.500 & \\
\hline 500.6 & 1.033 & 503.21 & 2.220 & 359.71 & 8.418 & 170.472 & \\
\hline 600.0 & 1.054 & 607.16 & 2.409 & 434.96 & 16.289 & 165.718 & \\
\hline 700.0 & 1.077 & 713.35 & 2.573 & 512.45 & 28.859 & 69.737 & \\
\hline 850.5 & 1.152 & 821.94 & 2.718 & 592.34 & 47.741 & 48.693 & \\
\hline 900.0 & 1.125 & 932.89 & 2.849 & 674.59 & 75.266 & 34.318 & \\
\hline 1000.0 & 1.145 & $1,045.98$ & 2.968 & 758.98 & 113.993 & 25.177 & \\
\hline 1100.0 & 1.161 & $1,166.86$ & 3.077 & 845.16 & 166.931 & 18.912 & \\
\hline 1200.0 & 1.176 & $1,277.30$ & 3.179 & 932.89 & 237.592 & 14.496 & \\
\hline 1350.6 & 1.190 & $1,395.16$ & 3.273 & $1,022.66$ & 330.047 & 11.365 & \\
\hline 1400.0 & 1.203 & $1,514.32$ & 3.361 & $1,112.52$ & 448.946 & 8.950 & \\
\hline 1500.0 & 1.214 & $1,634.66$ & 3.444 & $1,204.16$ & 599.548 & 7.181 & \\
\hline 1650.0 & 1.224 & $1,756.97$ & 3.523 & $1,296.87$ & 787.755 & 5.829 & \\
\hline 1700.0 & 1.233 & $1,878.46$ & 3.597 & $1,390.56$ & $1,020.145$ & 4.783 & \\
\hline 1850.0 & 1.242 & $2,051.73$ & 3.667 & $1,485.13$ & $1,354.093$ & 3.962 & \\
\hline 1900.0 & 1.250 & $2,125.80$ & 3.734 & $1,580.50$ & $1,647.343$ & 3.310 & \\
\hline 2005.0 & 1.256 & $2,250.60$ & 3.798 & $1,676.59$ & $2,058.949$ & 2.788 & \\
\hline 2100.0 & 1.263 & $2,376.56$ & 3.860 & $1,773.35$ & $2,548.392$ & 2.365 & \\
\hline 2200.0 & 1.268 & $2,502.11$ & 3.918 & $1,870.70$ & $3,126.568$ & 2.620 & \\
\hline
\end{tabular}

Figure 5. Sample thermodynamic properties table generated by the Gas Thermodynamic Properties Program.

"Proceedings of the 2005 American Society for Engineering Education Annual Conference and Exposition Copyright (C2005, American Society for Engineering Education", 
Simple Aircraft Gas Turbine Design (SAGTD): The 'Simple Aircraft Gas Turbine Design' software is essentially a tool to design and analyze a simple aircraft gas turbine. The major features are as follows:

1) Design a simple aircraft gas turbine engine with inputs provided by the user.

2) Use either Constant or Variable Specific Heat assumption for air properties

2) Compute and display all the key performance characteristics for the engine

3) Print a detailed report for the current design, including input data, calculated state data, and performance characteristics.

3) Plot graphs of performance characteristics vs. input parameters.

4) Save input data for current design as a file, which can be used later.

Figure 6 shows the opening screen of SATGD with the Specific Heat menu selected. The user may choose to perform all analyses with either Variable or Constant Specific Heat assumptions. This figure also shows the other available menu items, and the Tabs for selecting screens for entering data and viewing results.

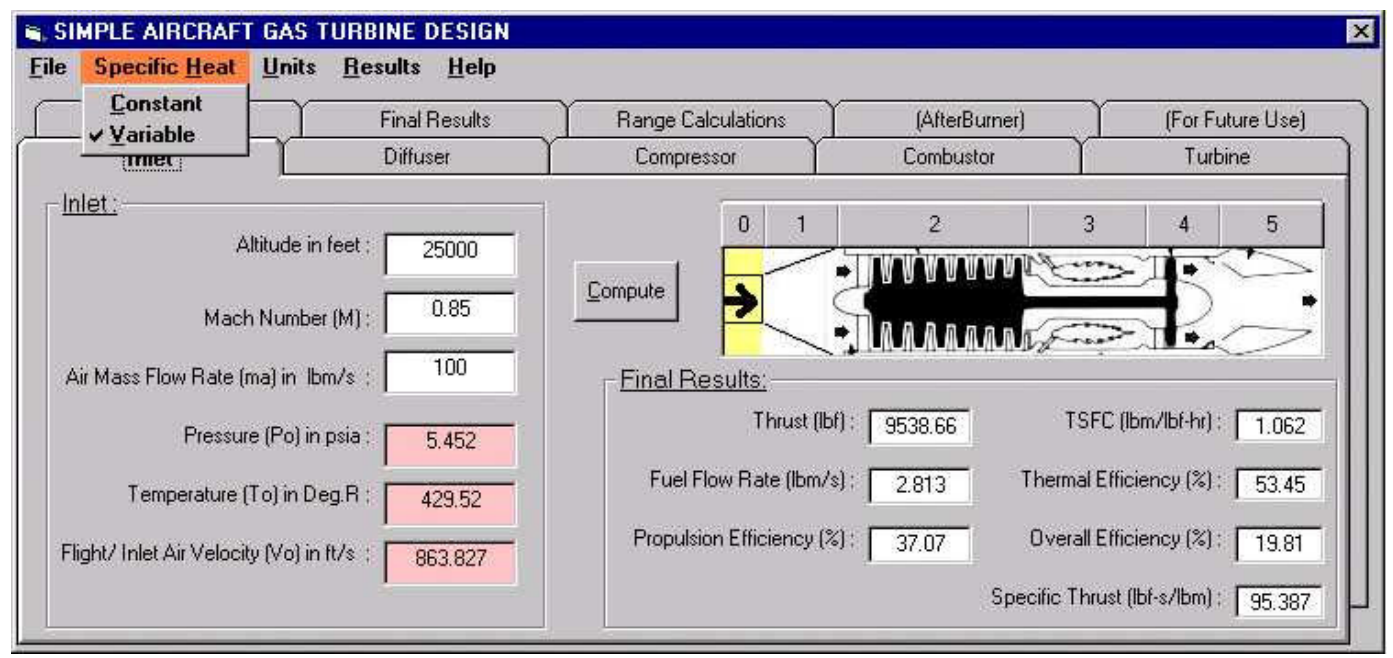

Figure 6. Snapshot of opening screen with 'Specific Heat' menu item clicked.

Figure 7 shows the main screen of SATGD with the Compressor Tab selected. The left side of the screen is used for user input of Compressor data. Notice the radio buttons allowing the user to choose the kind of information to be entered. The figure also shows a Compute button. When the Compute button is pressed, the compressor work is computed and displayed, the remainder of the engine is analyzed and seven different engine performance measures are computed and displayed under the diagram of the engine.

The user may use the tabs to navigate from one section of the engine to another, or the user may click on the numbered button above the engine schematic. For example, clicking on button 4 will have the same effect as clicking on the Turbine tab. The turbine input screen will be displayed. 
For a full analysis of an engine, the user should define the input data for each of the six sections of the engine. With the engine fully defined, the final results become meaningful.

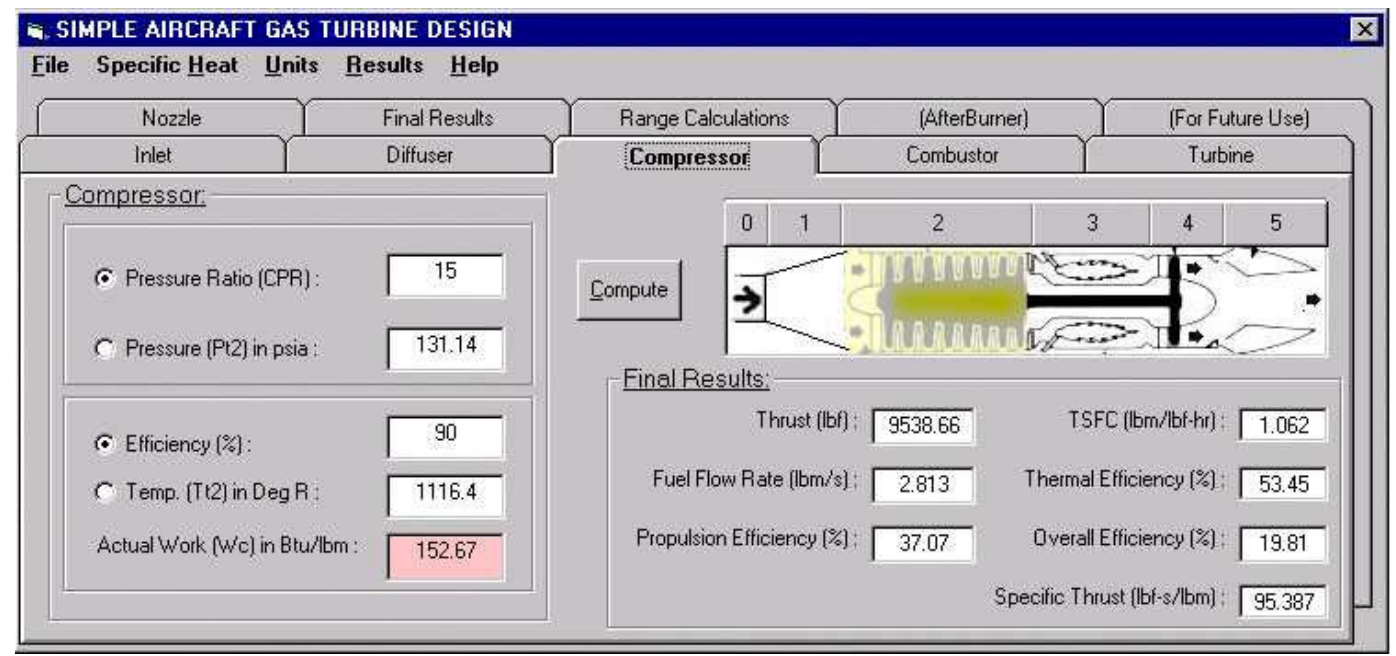

Figure 7. Program snapshot with 'Compressor' tab clicked.

Figure 8 shows the main screen of SATGD with the Range Calculations Tab selected. On this screen the user enters the initial and final weights of the aircraft, the wing area, and the aircraft lift and drag coefficients. With this input, the Cruise Velocity and the Range of the aircraft may be computed and displayed.

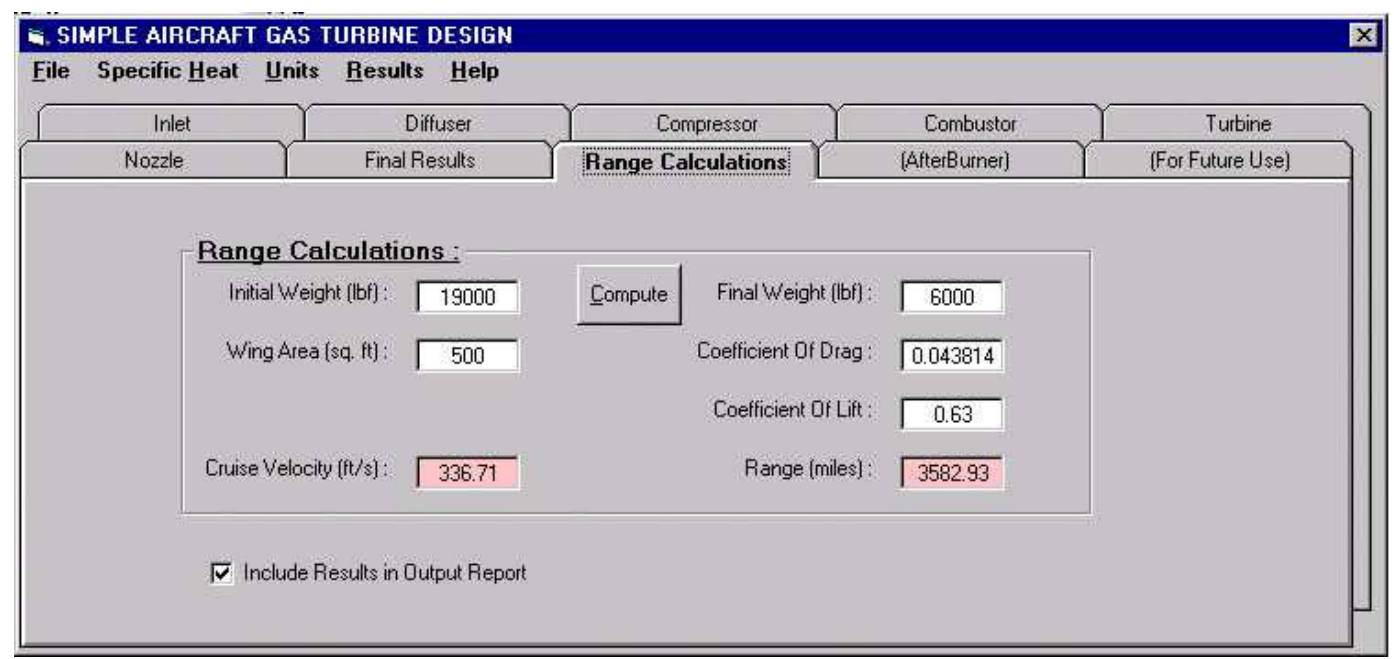

Figure 8. Program snapshot with 'Range Calculations' tab clicked. 
Figure 9 shows the main screen of SATGD with the Final Results Tab selected. The left side of the screen repeats the key user inputs. The right side of the screen shows the computed measures of performance.

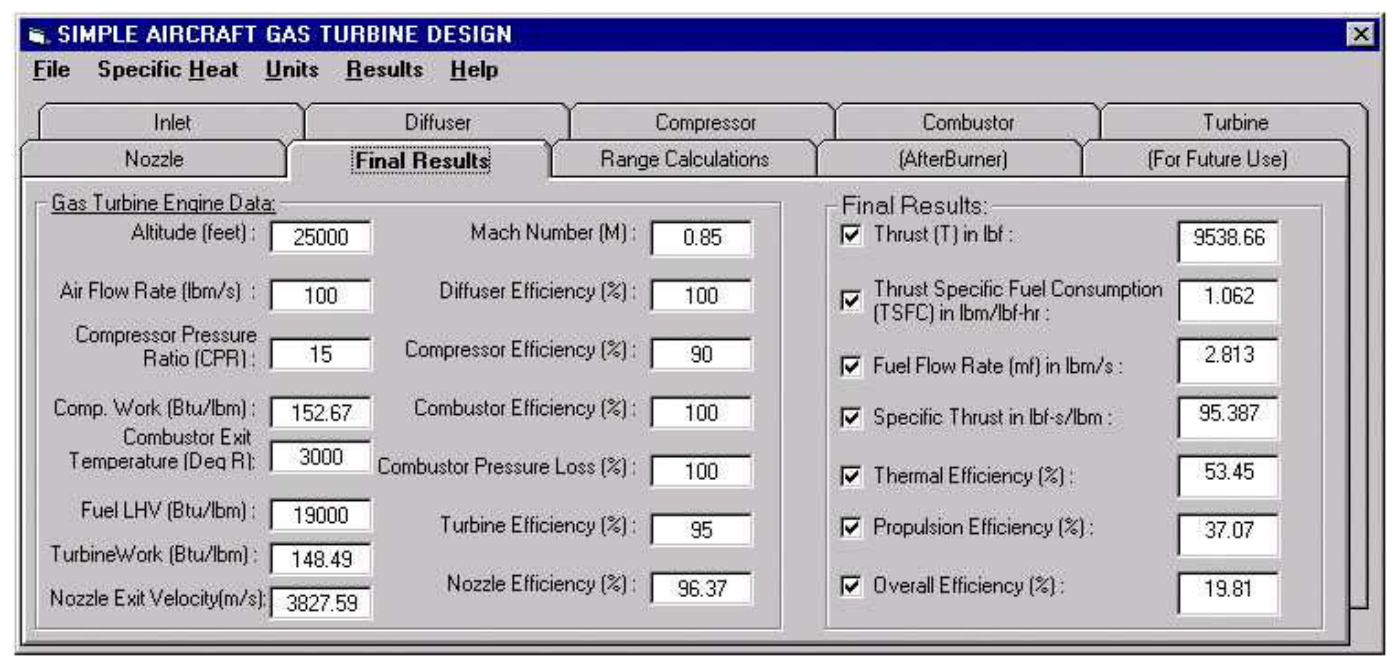

Figure 9. Program snapshot with 'Final Results' tab clicked.

Figure 10 shows the Design Report produced when the -Results - Print Report menu item is selected. The report shows all key inputs to the program, the key properties at each state in the cycle, and all of the engine performance measures including the Range calculation. The report can be saved as a text file for easy inclusion into a design report. 


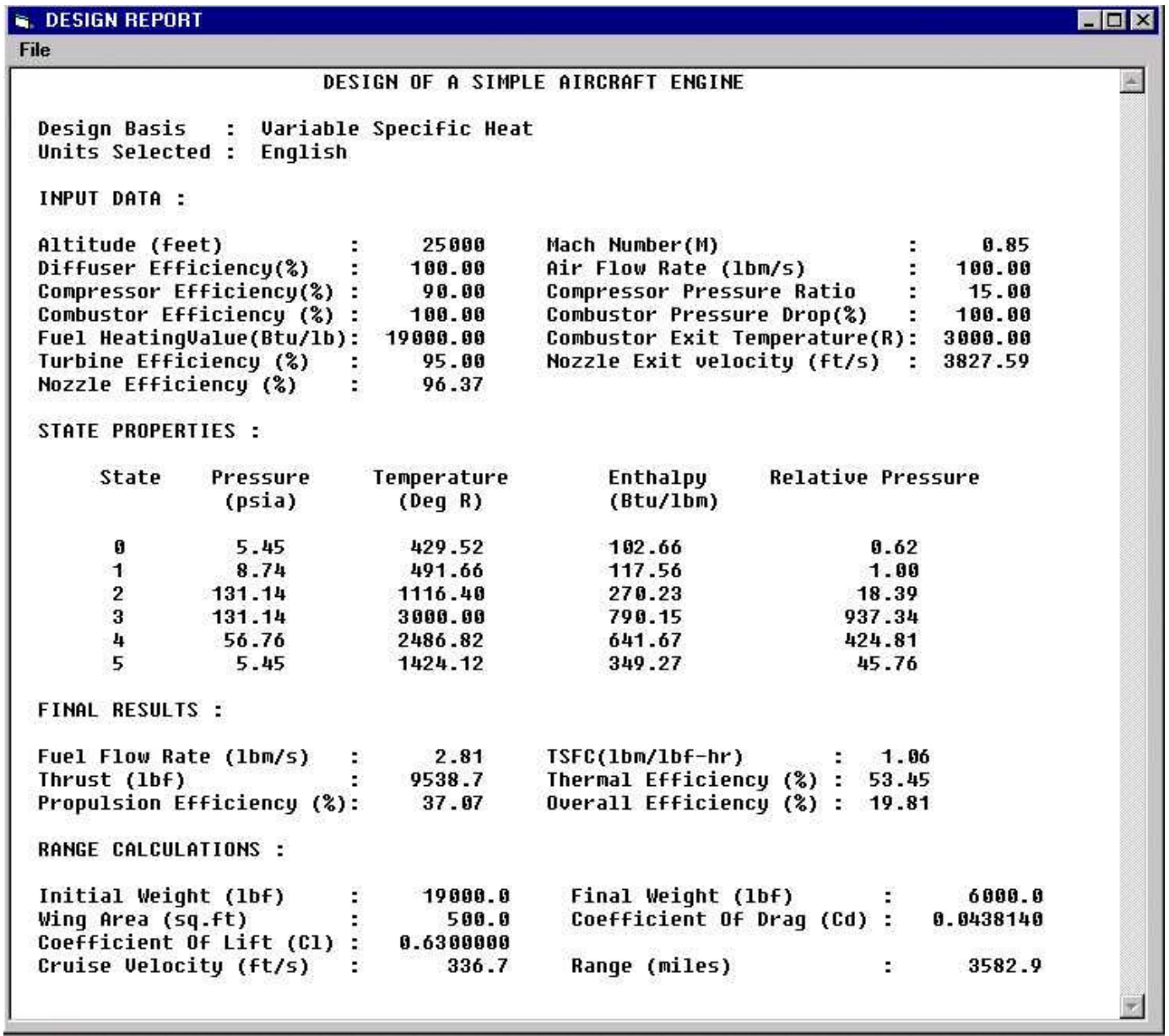

Figure 10. Program snapshot of the 'Results - Print Report' menu item clicked.

Figure 11 shows one of the graphs produced when the 'Results - Plot Graphs' menu item is selected. This is one of twenty different graphs that can be produced, by selecting one of five different output variables, and one of four different input variables. The available output variables are: specific thrust, TSFC, thermal efficiency, propulsion efficiency and overall efficiency. The available input variables are: Compressor Pressure Ratio, altitude, Mach number and maximum temperature.

The "Other Inputs" section of the screen allows setting specific values for any one of the input variables not currently being used for plotting. In this example, CPR in the graph input variable, spanning a range from 15 to 30. This particular plot corresponds to an altitude of 25000 feet, and a Mach no. of 0.85 . If the user wishes, they can change the values of any of the "other inputs" to produce a different graph.

This graphing facility allows the user to perform significant studies on the effects of the many input parameters on the performance characteristics of the engine. 


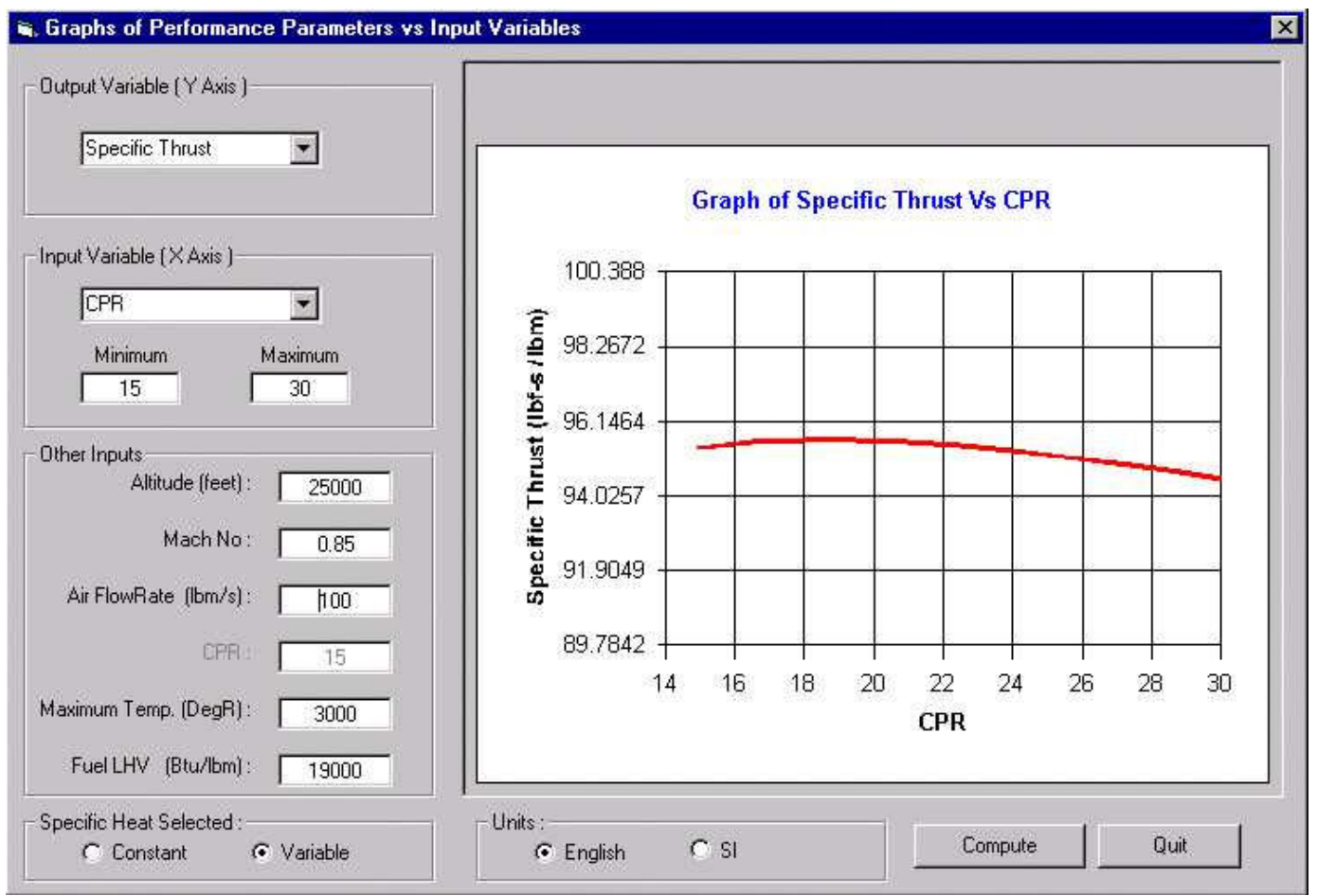

Figure 11. Program snapshot after 'Results - Plot Graphs' menu item was selected.

\section{Description and Evaluation of Classroom Use}

The Simple Aircraft Gas Turbine Design (SAGTD) software has been used in the Gas Power Systems course (MAE 4243) at Oklahoma State University for two semesters. The MAE 4243 course is taken by both mechanical and aerospace engineering majors in their senior year. The course is required for our aerospace engineering majors. For our mechanical engineering majors, the course is one of the four courses that the students must take under the "Thermal Systems Realization" category. The enrollment in the course is limited to 45 students with roughly equal distribution of mechanical and aerospace engineering majors.

In the first half of the course the software was mainly used as a homework solution tool. After first solving several problems by hand, the students then used the software to solve the same problems and additional homework problems that were calculation intensive. This gave the students a good understanding of the engineering fundamentals and equations that were used to develop the software. Many different kinds of homework problems were completed by the students with this software - from total engine analysis to specific component analysis.

In the second half of the course the software was used as part of a design project where the students observed the effect of changing several design variables on various turbojet engine performance parameters. Some of the design variables that were changed included: altitude, Mach number, engine maximum temperature, compressor pressure ratio, efficiency of the different components of the turbojet engine (inlet diffuser, compressor, combustor, turbine, and exit nozzle). Some of the observed engine performance parameters included: thrust, thrust specific fuel consumption, propulsion efficiency, thermal efficiency, overall efficiency, and 
aircraft range. Using the results produced from the SAGTD software, plots were produced for trend analysis. Based on these results the students then explained and discussed their recommended engine design parameters for the set of realistic constraints they were given for the design project.

Based on the end of the semester student surveys, direct input from the students during the semester, and input from the teaching assistants assigned to the course, the software program was very useful and easy to use. One student commented that "the SAGTD program interface was very easy to understand - making the program simple to work with. In my personal experience, there were no problems with the program in this respect. The learning curve for the program was basically nonexistent. Better said, with some very basic computer knowledge no time nor practice was required for successful utilization of the program". In working on the design projects, one student commented that "the SAGTD was very supportive in performing large amounts of calculations - making the creation of graphs a much less time consuming task". Another student's comment was "without this software a student is greatly limited in the performance effects he or she can see from varying engine component characteristics. This software greatly improves the student's ability to understand these effects therein improving his or her understanding of the turbojet engine as a whole. I learned most about the specific component characteristic's effects on the total engine output performance from working on projects for this class. SAGTD saved a large amount of time in the calculation performing phase of the projects and allowed me to understand how each component played into the whole picture faster".

In summary, the software was very well received by the students and their interest in the topic increased while using the software. The students found the software very easy to use and very helpful in greatly helping them with the understanding of the material. They were able to easily explore the effects of different design variables on the turbojet engine performance.

\section{Conclusions}

The 'Simple Aircraft Gas Turbine Design' software has met all the main objectives that were set initially. The objectives met are as follows:

1) Availability of source code now, makes it possible to add new modules such as one for optimization of various performance characteristics of the gas turbine engine. Also it is very easy to make minor changes to the program.

2) Easier for users to make changes to the input parameters at any stage of the design.

3) Users can view changes of the performance characteristics instantly whenever he/she makes any changes to the input parameters.

4) Plot graphs of the key performance characteristics vs. input parameters for a given gas turbine.

5) A design tool for quick and easy design of a 'Simple Aircraft Gas Turbine'.

Software offer: The authors believe that this software might be of use to other universities offering similar courses. We would be glad to make the software and documentation available to other faculty, at no charge. Please contact either of the first two author's at Oklahoma State University, School of Mechanical and Aerospace Engineering.

\footnotetext{
"Proceedings of the 2005 American Society for Engineering Education Annual Conference and Exposition Copyright $\mathbb{C} 2005$, American Society for Engineering Education"
} 


\section{References}

1. Bathie, William W., 'Fundamentals of Gas Turbines', 2nd ed., John Wiley and Sons, New York, 1996.

2. Keenan, J. H., 'Thermodynamics', John Wiley and Sons, New York, 1941.

3. Wark, Kenneth, 'Thermodynamics', 4th ed., McGraw-Hill, New York, 1983.

4. 'NASA SP-273', US Government Printing Office, Washington, 1971.

5. Keenan, J. H. and Kaye, J., 'Gas Tables, Thermodynamic Properties of Air', John Wiley and Sons, New York, 1948.

6. 'US Standard Atmosphere 1976' - NOAA, NASA, USAF, October 1976.

\section{Biographical Information}

Afshin J. Ghajar is a Regents Professor and Director of Graduate Studies for the School of Mechanical and Aerospace Engineering at Oklahoma State University. He received his B.S., M.S., and Ph.D. in Mechanical Engineering at Oklahoma State University. His research interests include Two-Phase Flow Heat Transfer, Heat Transfer in Mini/Micro Channels, Mixed Convection Heat Transfer, and Computational Heat Transfer and Fluid Mechanics.

Ronald D. Delahoussaye is a Lecturer and Director of Undergraduate Studies for the School of Mechanical and Aerospace Engineering at Oklahoma State University. He received his B.S. Mechanical Engineering at Louisiana Tech University, M.S. Mechanical Engineering at Georgia Institute of Technology, and Ph.D. in Mechanical Engineering at Oklahoma State University. His research and teaching interests include Mechanical Design and Computer Aided Design.

Vandan V. Nayak received his Bachelors of Engineering from Victoria Jubilee Technical Institute, Mumbai, Maharashtra, India, and his M.S. Mechanical Engineering from Oklahoma State University. He currently works for Mercury Interactive, located in Mountain View, California. 